Papers and Proceedings of the Royal Society of Tasmania, Volume 115, 1981

(ms. received 9.9.1980)

\title{
ABORIGINAL SKELETAL REFIAINS FROM CAPE PORTLAND
}

by Peter Murray and Don Ranson

Tasmanian Museum \& Art Gallery, Hobart and

National Parks $ॄ$ Wildlife Service, Sandy Bay Tasmania

(with three tables, two text figures and four plates)

ABSTRACT

MURRAY, Peter and RANSOM, Don, 1981 (30 ix): Aboriginal skeletal remains from Cape Portland. Pap. Proc. R. Soc. Tasm., 115, 69-76 (with two figures and four plates). https://oi.org/10.26749/rstpp.115.69 ISSN 0080-4703.

Tasmanian Museum and Art Gallery and National Parks and Wildlife

Service, Hobart, Tasmania, Australia.

An abori inal cranium and manible (M4903) was recovered from a deflated midden deposit within the National Parks and Wildlife Reserve on the Cape Portland Estate, Cape Portland, northeastern Tasmania. No aditional skeletal material was found during follow up excavation procelures that took place about two weeks after the iscovery. The skull is within the known morphological range for Tasmanian aboriginals.

\section{INTRODUCTION}

A Tasmanian Aboriginal skull (Tasmanian Museum No. M4903) was discovered in a deflated midden deposit at Cape Portland by naturalist Ralph Cooper of Legana. The skull, (complete cranium and mandible) and some fish bones were presented to the museum by Piers Allbrook and Dee Mills of Hobart, shortly after the discovery which took place in February 1980. The cranium and mandible were removed from the site after their positions were marked because the prevailing wind had shifted and had commenced refilling the deflated surface upon which the remains were found.

The Tasmanian National Parks Service was informed of the find and an expedition to recover additional remains was set for the following weekend (Feb. 29 th-March 2 nd).

\section{EXCAVATION}

Mr Cooper kindly met us at Cape Portland and led us to the site (fig. 1). The human remains were located in a deflated midden (sheet 8416/EQ809858) that extends for about 0.5 $\mathrm{km}$ in a northwesterly direction. For several hours the surface was searched for human skeletal remains. No additional skeletal material was found. A grid system of 1 metre squares was laid out over the general area from which the cranium and mandible were recovered.

This area was trowelled down to $0.05 \mathrm{~m}$ below the surface and an adjacent test pit was dug to a depth of 0.5 metres. The sand lying directly below the surface proved to be sterile to .5 metres, indicating that all of the midden material and human remains were derived from deflated sediments lying above the surface from which they were removed.

\section{MIDDEN CONTENTS}

The midden contains remains of both vertebrate and invertebrate food items, bone and stone artifacts and some invertebrate remains that had been blown into the area (mostly tests of the sea urcinin Holopneustes and cuttlefish). Invertebrate food remains include warrener, abalone, scallop, mussels, several small gastropod genera and limpets. Vertebrate food remains include sea lion, fur seal, swan, duck, Bennett's wallaby, forester kangaroo, mutton bird and fish remains, including parrot fish. A bone point made from wallaby fibula was found about $14 \mathrm{~m}$ from the human remains (plate 1 ). None of the material was in its original stratigraphic context although adjacent intact middens may be 


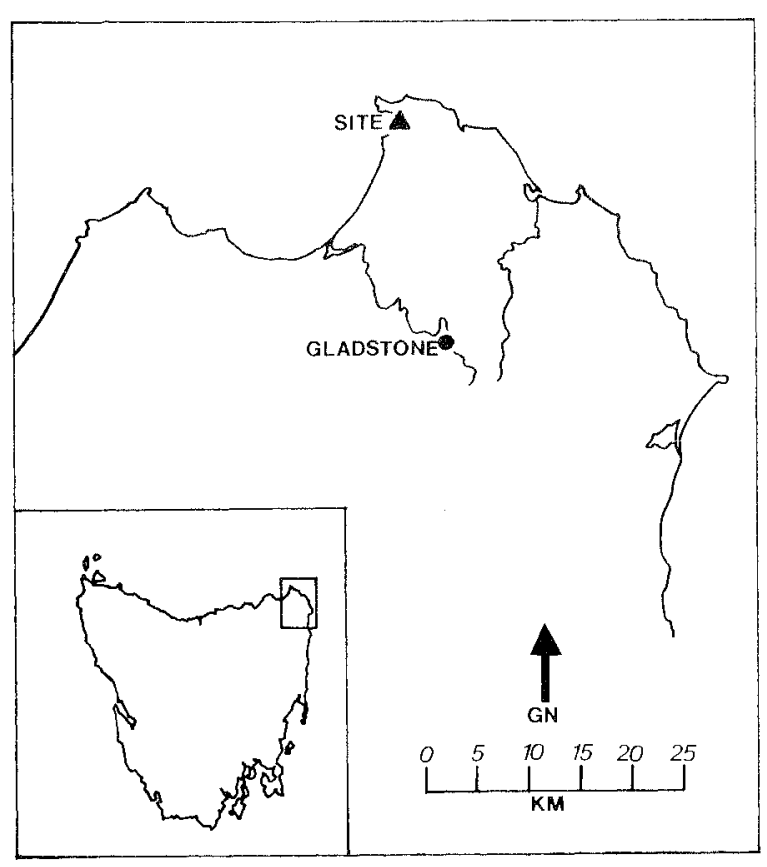

FIG.1. - Map of locality, Capt Portland, nor theastern Tasmania.

contemporaneous with the deposit. These middens were also undergoing rapid erosion. They are largely confined to a thick organically stained calcarenite that is overlain by up to 15 soil horizons comprising the large dune system that dominates the area. Root casts are associated with many of these exposures.

\section{DATING}

Unless the rest of the skeleton is located in situ it will not be possible to assign a date to the skull. An attempt to use relative sluorine content of bone was thwarted by a lack of clear stratigraphic continuity between the various deposits.

\section{DESCRIPTION}

The specimen consists of a nearly complete cranium and mandible (plate 2). The cranium shows slight erosion of the vault due to sand blasting and rootlet invasion. Faint streaks of mineral stain are also present. There is some damage to the posterior portion of the palate and both temporal bones have irregular holes through them located just above the auditory meatus. The tips of the nasal bones are damaged and both zygomatic arches are broken. The right central and left central and lateral maxillary incisors and the right upper first molar are missing. The mandible lacks the right central incisor and the tip of the right coronoic process.

l'he skull probably represents a male between 20 and 30 years of age. The patent sphenoidal-basioccipital suture suggests the lower 20 's. The third molars are fully erupted and well worn.

The braincase is long relative to width (cranial index $=71$, dolichocephalic), with an estinated cranial capacity of $1380 \mathrm{cc}$. The external occipital protuberance and associated nuchal muscle markings are only moderately well expressed. The temporal bone is broad with slight supraciliary brow ridges. Glabella is not prominent nor is nasion very deeply depressed. The parietal eminences are poorly expressed. The vault has a pentagonal outline resulting from a shallow convexity in the parietals on either side of the sagittal suture. Obelion is slightly depressed. Wormian bones are absent in the lambdoidal suture. The auditory meatus is roofed by a well developed suprameatal crest. Auditory meatal exostoses are present on both sides. The mastoid processes are eroded, but are of medium size for a Tasmanian male. The digastric groove is relatively narrow and shallow. The orbits are wide and low (orbital index $=67$ ). The nasal bones are much abbreviated and convex. The nasal aperture is relatively long and narrow for a Tasmanian (nasal index $=54.0$ ). The upper face is short.

The cranium displays maxillary prognathism (gnathic index $=106$ ). The palate is relatively deep and broad. The teeth are large and attrition is marked. Interproximal wear is present on all molar crowns. Moderate to severe alveolar recession is evident. An anomalous root is present in its own alveolus buccal to the second premolar on the left sicie. A similar growtin appears apically on the right second premolar. The right first premolar shows alveolar erosion due to an apical abscess and there is a small, 
corresponding exposure on the crown.

The mandible is stout with a neutral chin and a poorly defined mental trigone. The digastric fossae are well developed and genial spines are present. The gonial angles are moderately everted. A similar degree of alveolar recession is present on the mandible.

M4903 is both metrically and morphologically within the known range for Tasmanian aboriginals and there is no reason to consider its affinity with any other racial group. It combines both minimal and maximal expressions of morphological features generally accepted as being characteristic of Tasmanian aboriginal populations.

Its features are generally delicate. The parietal eminences are only slightly expressed and there is no impression of a sagittal keel. Obelion is just

perceptibly depressed. However, the external occipital protuberance is well developed, the suprameatal crest is prominent, the orbits are very low and wide and the face is short, broad and prognathous. Despite the moderate expression of many of the characteristic traits, the skull retains an overall form that is distinctly Tasmanian. This is seen in the conformation of the cranial vault, and morphology of the face and palate. The mandible is typical of Tasmanian aboriginal males.

This is the second skull found at Cape Portland. A previous discovery took place in March 1924 apparently under similar conditions. Occurrences of human remains are rarex on the north-east coast than on the west. Ten provenances are recorded from the entire east and northeast coast in the short distance between Mt Cameron West and Temma. Discoveries are still rarer from the southeast and south where only nine localities are recorded. It does not seem likely that material lacking provenances

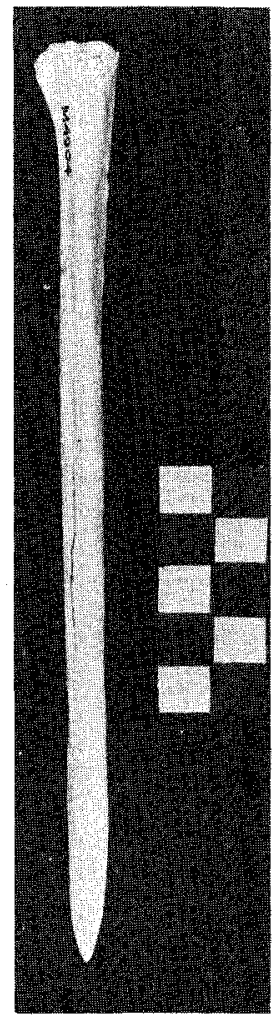

PLATE 1.- Bone point collected from surface near skeletal remains. could account for this discrepancy. Factors such as burial/cremation practices, population size and preservational environment may be responsible.

The 1924 Cape Portland cranium (TS83) displays well developed parietal bosses, markedly convex parietals and a depression around obelion. The individual is smaller, probably a male, and is somewhat older, judging from the complete closure of the basioccipital-sphenoidal suture. There is also more attrition of the molars, and evidence of osteo-arthritis on the occipital condyles and glenoid fossae (fig. 2).

Populations in the northeast appear to exhibit about the same degree of individual variability as from from other parts of Tasmania suggesting the presence of social mechanisms leading to liberal gene flow throughout the island. Tasmanian aborigines express a comparatively high degree of morphological homogeneity, as a result of a small population size and genetic isolation. 

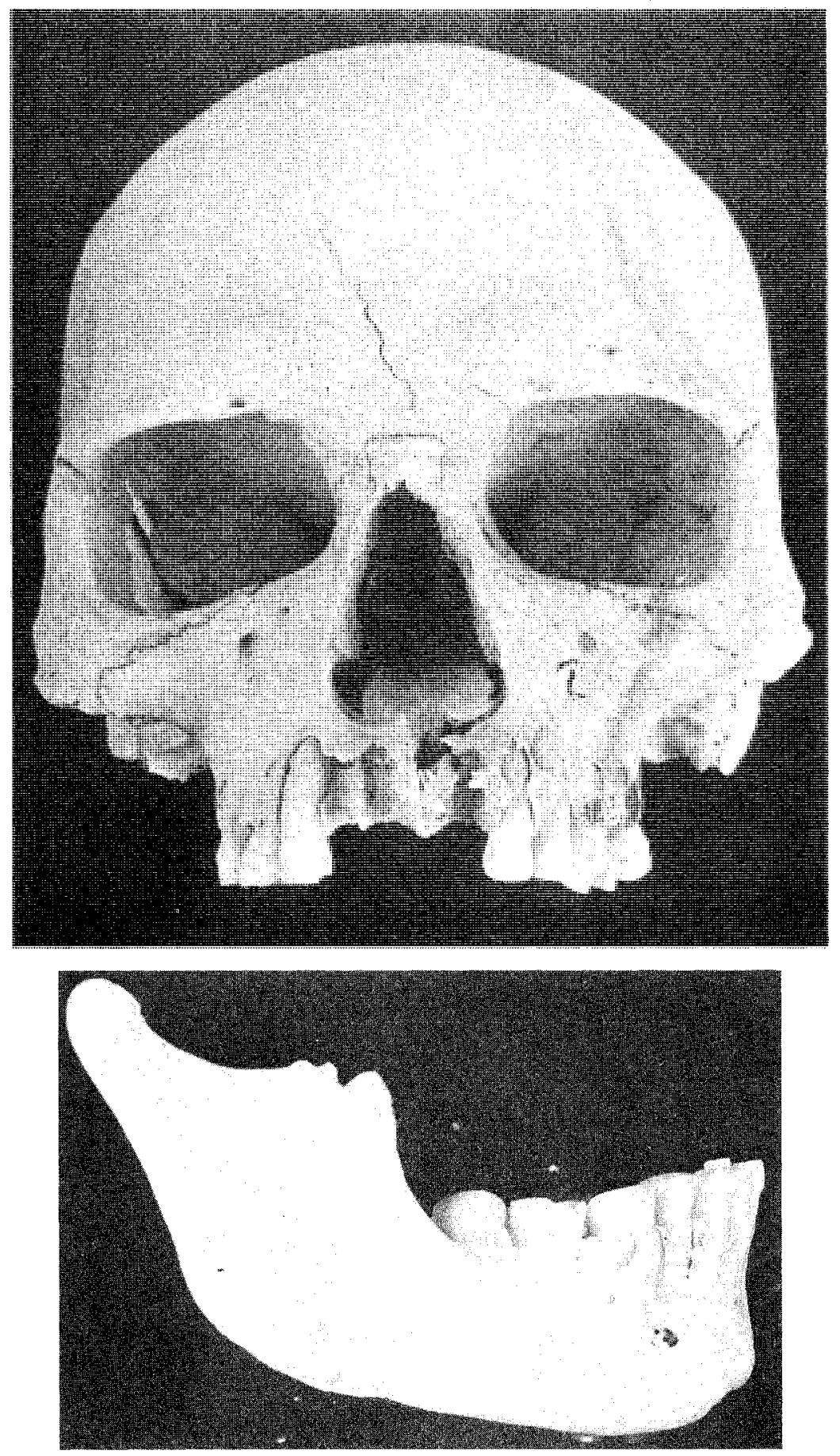

PLATE 2, - Photographs of cranium and mandible. 
Peter Murray and Don Ranson

TABLE 1

METRIC AITRIBUTES OF M4903

Maximum eralial length

Maximum breidth

Minjmum froital breadth

Basi-breg height

upper facial height

nasal height

nasal breadth

orbital height

orbital breadth

palatal breadth

palatal depth

maximum palatal width

maximum palatal length

minimum ascending ramus breadth

symphyseal height

minimum horizontal ranus height

Cranial Index (dolichocephalic)

Gnathic Index (prognathous)

Orbital Index

Nasal Index

Cranial Capacity - $1380 \mathrm{cc}$

\begin{tabular}{|c|c|c|}
\hline M4903 & $\begin{array}{l}\bar{X} \text { TASMANIAN } \\
\text { (Wunder } 1 y^{\prime} 39 \text { ) }\end{array}$ & $\begin{array}{l}\text { (Males) } \\
(\text { Morant } 27\end{array}$ \\
\hline 183.0 & 185.4 & 182.2 \\
\hline 129.0 & 138.2 & 136.0 \\
\hline 97.0 & 94.7 & 94.0 \\
\hline 126.5 & 129.8 & 130.9 \\
\hline 60.5 & 62.4 & 62.5 \\
\hline 48.0 & 45.1 & 47.1 \\
\hline 26.0 & 26.9 & 27.8 \\
\hline 28.0 & 29.3 & 31.1 \\
\hline 42.0 & 37.9 & - \\
\hline 42.0 & - & - \\
\hline 15.0 & - & - \\
\hline 65.0 & - & - \\
\hline 62.5 & - & - \\
\hline 34.0 & - & - \\
\hline 25.0 & - & - \\
\hline 24.5 & - & - \\
\hline 71 & 74.2 & 74.2 \\
\hline 106 & 101.4 & - \\
\hline 67 & 78.2 & - \\
\hline 54 & 59.9 & 59.1 \\
\hline & $1247 \mathrm{cc}$ & $1264 \mathrm{cc}$ \\
\hline
\end{tabular}

TABLE 2

GLASSIFICATION OF MOLAR WEAR (Brothwe11 1972)

$\begin{array}{lll}M^{1} & M^{2} & M^{3} \\ 5 & 4 & 3 \\ M_{1} & M_{2} & M_{3} \\ 5+ & 5+ & 4\end{array}$

TABLE 3

MEASUREMENT OF: TEETH

Mesiodistal Buccolingual

$\begin{array}{lc}\mathrm{I}_{\overline{1}} & 4.6 \\ \mathrm{I}_{\overline{2}} & - \\ \mathrm{C} & - \\ \mathrm{P}_{\overline{1}} & - \\ \mathrm{P}_{\overline{2}} & 7.1 \\ \mathrm{M}_{\overline{1}} & 10.6 \\ \mathrm{M}_{\overline{2}} & 11.6 \\ \mathrm{M}_{\overline{3}} & 11.5\end{array}$

5.5
-
-
-
10.6
10.6
11.0
11.5

Mesiodistal

Buccolingual

$I^{1}$
$I^{2}$
$C$
$P \frac{1}{2}$
$M^{2}$
$M^{2}$
$M^{2}$

-
-
8.0
7.3
7.3
10.0
11.0
9.5

7.5
10.2
10.0
12.1
13.0
11.5


Aboriginal Skeletal Remains from Cape Portland
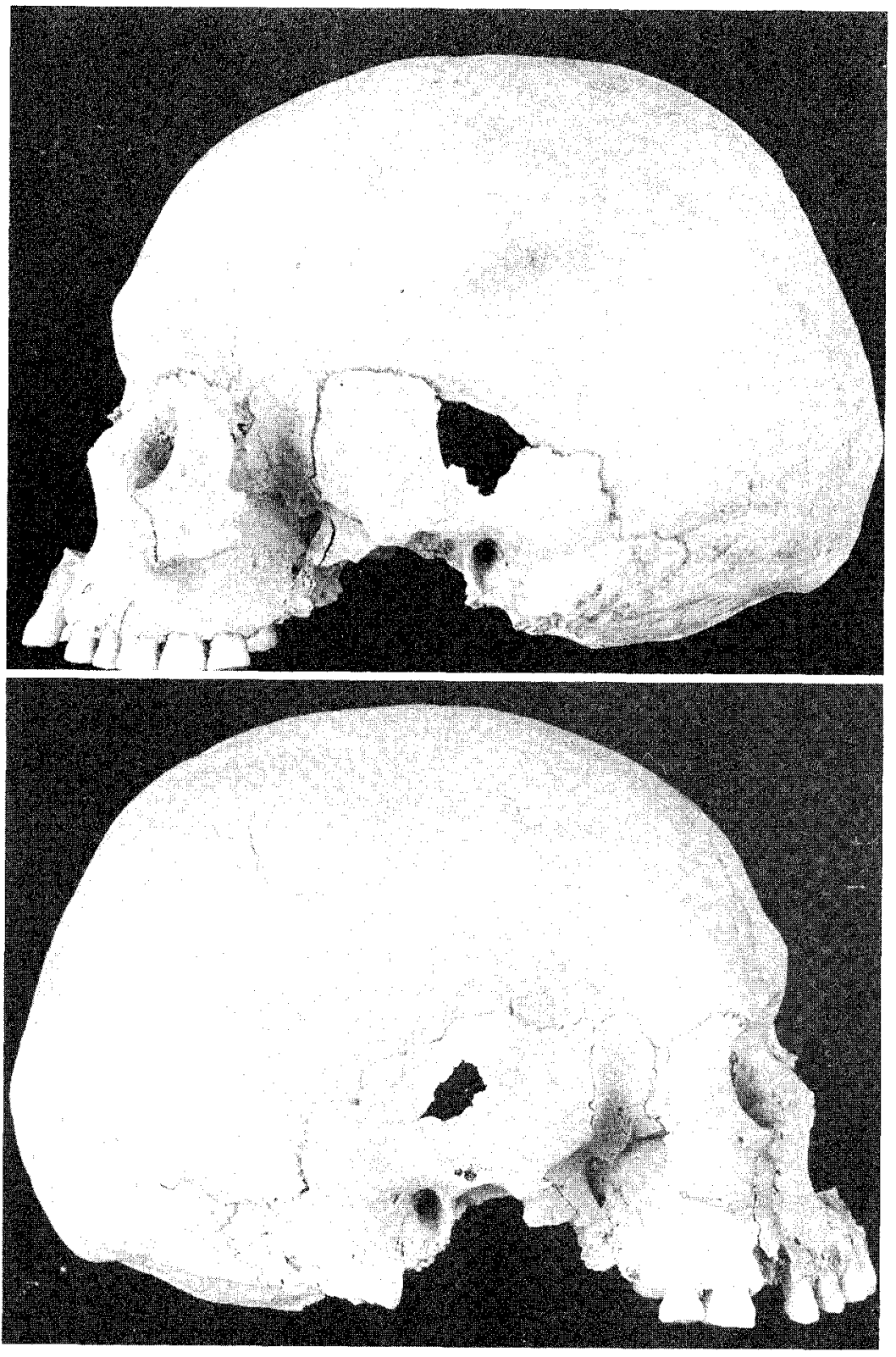

PLATE 3.- Lateral views of cranium. 

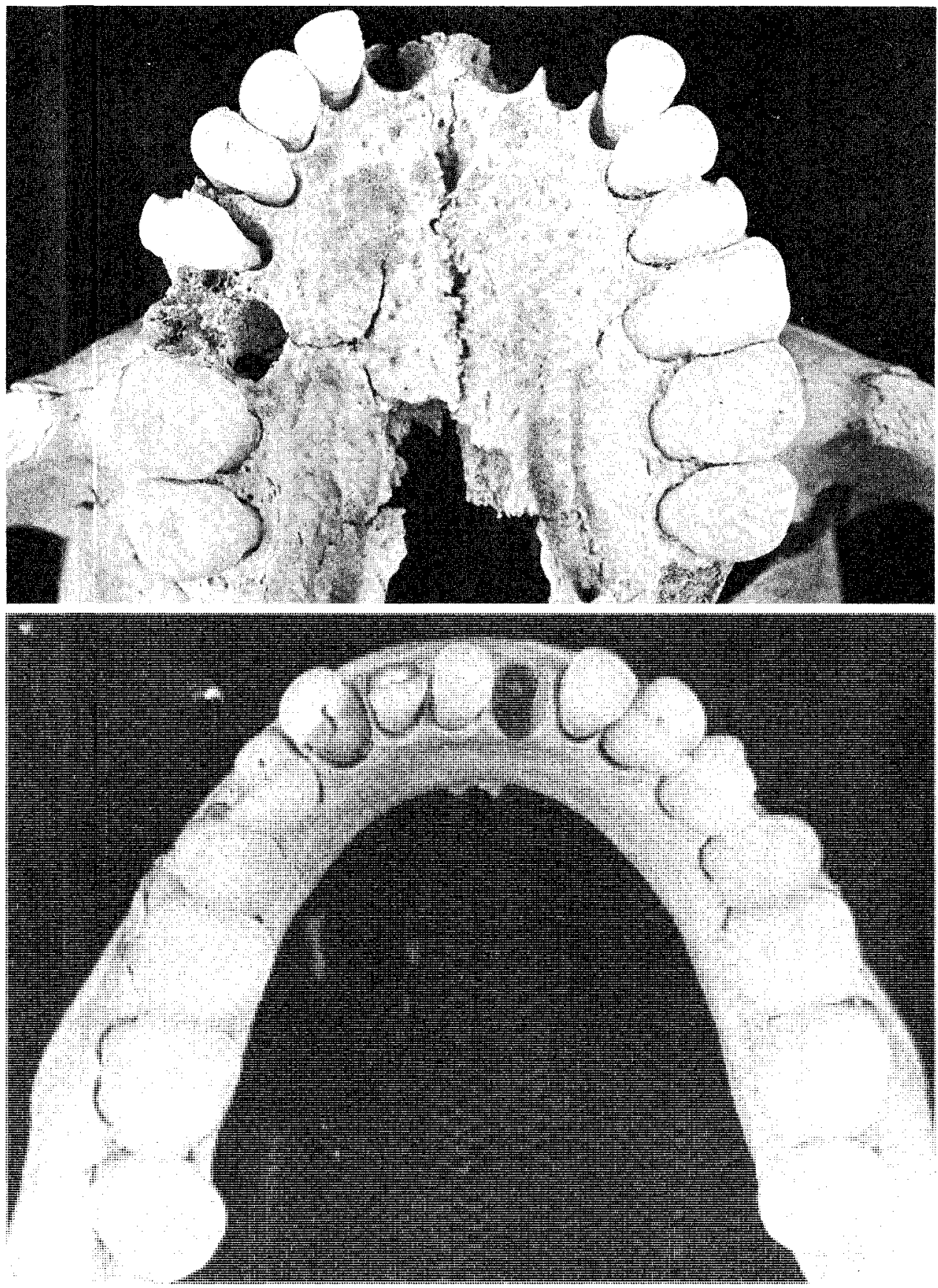

PLATE 4.- Maxillary and mandibular dentitions. 

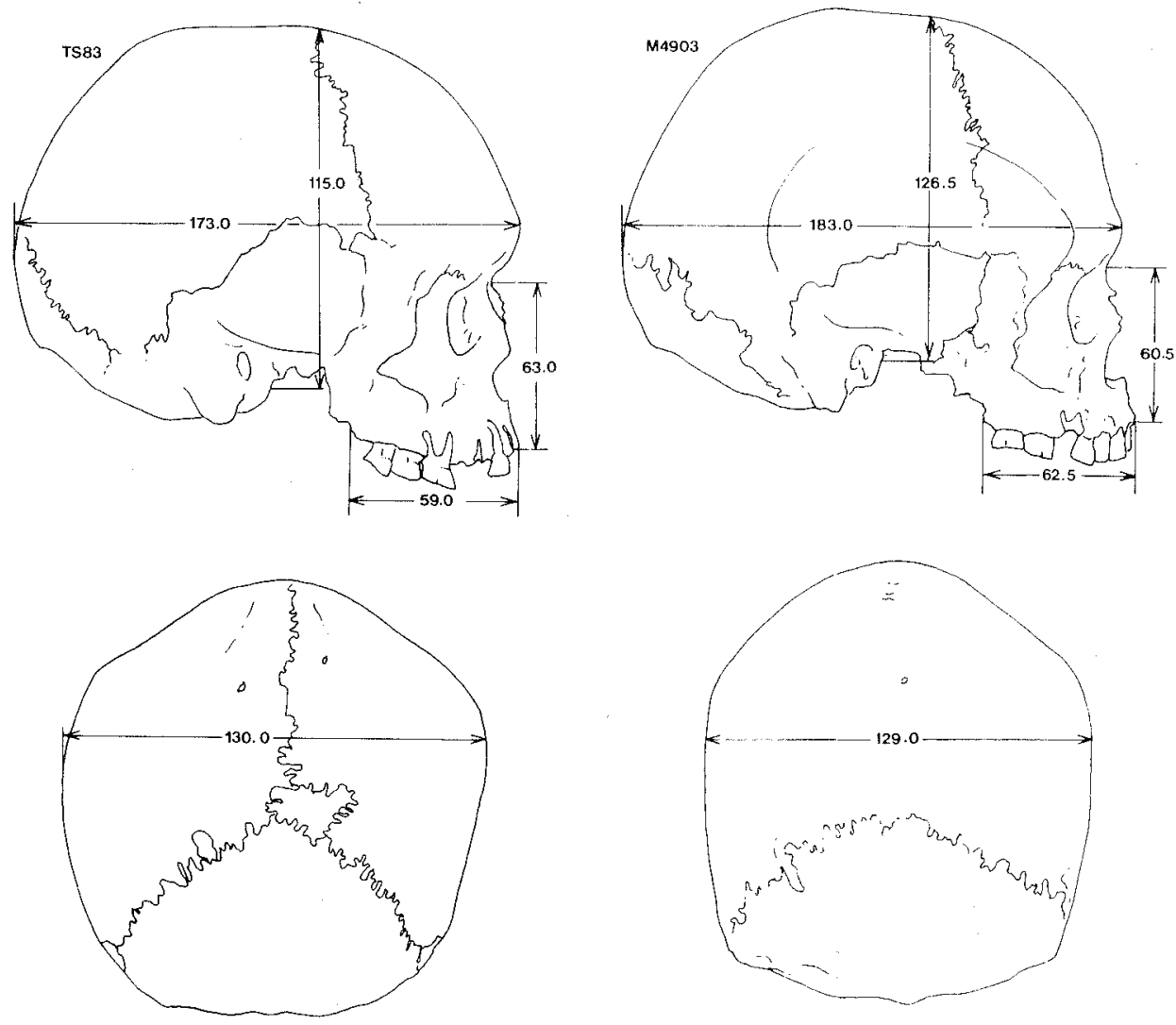

FIG. 2.- Comparison of TS83 and the new Cape Portland skull M4903.

\section{REFERENCES}

Brothwell, D.R., 1972: DIGGING UP BONES. British Museum Publication No. 704. Morant, G.M., 1927: A study of the Australian and Tasmanian skulls based on previously published measurements. Biometrika $19: 417-40$.

wunderly, J., 1939: The cranial and other skeletal remains of Tasmanians in collections in the Commonwealth of Australia. Biometrika 30 ( 3 \& 4j: 305-40. 